\title{
The Impact of Climate Change and Global Warming on Utilization of Crop Genetic Resources
}

\author{
Ardeshir B. Damania \\ Dept. of Plant Sciences, University of California, Davis, CA 95616-8602, USA; abdamania@ucdavis.edu; Tel.: \\ (+1) 530-754-8507 \\ Received: date; Accepted: date; Published: date
}

\begin{abstract}
A large number of collecting expeditions were launched in regions of 'centers of diversity' and hundreds of thousands of sample have been collected and stored in gene banks as 'genetic resources'. So far, only a small number of the samples have been evaluated for their biotic and abiotic stress tolerance. Now, their time to become useful has come. A new global phenomenon has arisen - climate change. The crop genetic resources and their wild progenitors that have survived countless years of changing environment during the last 11,000 years could harbor genes that may be useful under the new growing conditions and environmental factors thrown up by climate change and global warming. With the deployment of modern bio-engineering techniques selected genes or gene fragments can be transferred from genetic resources to modern varieties of crop plants to make them well-prepared to mitigate the effects of global warming and climate change. The latter is the most serious issue facing plant breeders today. New pests and diseases could affect crop production. These review paper discusses various impacts and issues as a result of this phenomenon and suggest ways to safeguard our most important crops through better management of crop plant genetic resources in the near future.
\end{abstract}

Keywords: Abiotic stress; Biotic stress; Adaptation; Climate change; Diseases; Diversity; Genetic Resources; Genebank; Wild relatives

\section{Introduction}

The disappearance of old varieties of crop and other species of plants have alarmed crop scientist since the 1960s. The mass elimination of a large number of indigenous crop plant varieties and their obsolete and wild genetic resources in the centers of their diversity does not bode well for combating the effects of climate change and global warming. Such losses of genetic resources has resulted in concerns about the future food supply and nutrition security. Climate change is a phenomenon, which needs to be focused on for a better and sustainable development. The augmentation of greenhouse gases in recent decades has led to global warming on a gigantic scale leading to melting of glaciers and very large chunks of ice caps breaking off in to the Sea. This intern leads to more precipitation, extreme heat and some place also cold, and more importantly shifting of seasons. There is little doubt that climate change will greatly impact crop plant genetic resources (Kumar, 2015). Threats to extinction have been identified for certain species as a result of impacts such as excessive collection of wild species from the forests for food, medicinal uses and other cultural uses, for instance in Turkey (Muminjanov and Karagöz, 2018).

Climate change has become one of the key drivers of biodiversity loss. However, genetic resources for food and agriculture are also expected to play a significant role in mitigation of and adaptation to the consequences of climate change in support of efforts to achieve food security and nutrition objectives. All over the world, farmers have been adapting their crops as well as their cropping systems to the changed circumstances they now face. However, recently the speed and complexity of the changes the farmers face present unprecedented challenges. New crop varieties will 
be needed to mitigate the effects of these changes and in some cases, farmers may have to also resort to change the crop varieties they traditionally grew. Those areas in South Asia and Africa that are currently the most food insecure will be worst affected by these changes and hence will have the greatest need for new varieties that are tolerant to drought, high temperatures, salinity, flooding and other abiotic and biotic challenges that may turn up. In addition, climate changes will also affect those habitats that harbor wild progenitors and relatives of domesticated crop plants. Wild species that are unable to rapidly to these changes will be particularly vulnerable to disappearance. Jarvis et al. (2008) have estimated that between 16 to 22 percent of wild relatives of crop plants may be under danger of extinction within the next 50 years.

Humanoids have been on this planet for at least 4.4 million years but agriculture is a fairly recent phenomenon having begun a little over 11,000 years ago (there is no archaeological evidence to show that it was practiced earlier)(Hole, 1998). Since then several hundreds of crop plants have been domesticated from the wild. However, valuable gene pool of our crop plants is being diminished daily in our time due to threats such as directional selection, deforestation, industrialization, and urbanization. 1. Loss of natural dispersal mechanisms. 2. Rapid germination. 3. Larger seeds. 4. Simultaneous ripening. 5. Loss of mechanical mean of protection. 6. Color changes and 7. Loss of toxic or bitter properties are some of the selection pressures that are applied on crop varieties. (Damania, 2008). During the last three decades erosion of genetic resources has taken place at pace rapid enough to cause utmost concern for the numerous old crop varieties and diverse other forms in their centers of diversity - one might even now say, with some justification, 'centers of former diversity'. For example, $95 \%$ of the indigenous wheat varieties in Greece have been replaced by improved Italian cultivars, and all the sorghum races of South Africa disappeared after the introduction of white high yielding varieties from Texas.

According to the U.S. National Academy of Sciences, climate change will be one of the most significant threats to agriculture and human society in general in the $21^{\text {st }}$ century. Pests and plant diseases are heavily influenced by climate. The geographical range of several pathogens and disease vectors are limited to climatic factors such as, lower temperatures during winter months. For example, higher winter temperatures increases the rust fungi (Puccinia graminis) infestation leading to lower yields in crop derived from grass species Such as, wheat, barley, oats, etc. (Pfender and Vollmer, 1999).

\section{Dangers of genetic uniformity and exploration to conserve genetic diversity}

There is clearly a trend towards morphological and genetic uniformity in the modern varieties of crop plants resulting in the narrowing of the genetic base and exposure to attack by new pathogens against whom the crop has no immunity. In other words, a narrow genetic base of a crop variety may lead to an increased risk of losses caused by new strains of parasites, insect pests, and diseases or due to unusual environmental phenomenon such as the 'green-house effect', climate change and global warming.

In 1845 and 1846 the late blight disease caused by a fungus (Phytophthora infestans) cut Ireland's potato production by half resulting in famine that cost hundred thousands of lives and triggered mass emigration, mainly to North America. The potato crop was devastated throughout Europe, but the population of Ireland was especially vulnerable. Clonal propagation of potatoes allowed the cultivation to continue up to that time with a narrow genetic base based on a single cultivar derived from closely related parentage (Damania, 2008). Consequently wild genetic resources of potato, collected mostly from the Andes in Peru, have been used to produce resistance not only to the late blight but also to other diseases such as bacterial wilt, scab, leaf roll, and a number of other pathogens. In 1990, Americans consumed 5 billion pounds of French fries from a total crop production worth 2 billion dollars. The late blight is still around and periodically attacks potato crops in the U.S. with new, more aggressive strains constituting a potential threat to potato production all over the country and the world.

Similarly, in 1970 a single hybrid maize variety that was planted over much of the South-east U.S. to the Great Plains was devastated by another leaf fungus, Helminthosporium maydis, resulting in 
losses to farmers totaling almost 1 billion dollars. A single gene, Tcms, present in over $80 \%$ of the plants was responsible for the corn's susceptibility to the new type of leaf blight. A crash breeding program to produce resistant strains without this gene and a broad genetic base was successful in averting a major catastrophe to the corn industry.

In Russia, due to a period of consecutive mild winters during the late 1960s, the high yielding winter wheat variety "Bezostaya" (Triticum aestivum L.) spread rapidly outside its original area of adaptation, so that by 1972 it occupied about 15 million hectares. But in that year harsh winters returned to Russia with a vengeance and damage to the crop was extremely high forcing that country to resort to imports to make up the deficit and avoid great human hardship. These catastrophic events and the general vulnerability found in our major crops around the world led to a series of genetic resources exploration and collecting trips around the world for greater diversity of genetic resources (Martynov and Dobrotvorskaya, 2006).

Climate change is obviously the 'virus' of nature and the most serious issue on earth which need to be focused for a better and sustainable development. Changes in the sun spot activity, earth's orbit, gases in the atmosphere and anthropogenic influences are the main causes which lead to change in climate. Climate change causes a cascade of negative effects on human health, agriculture, environment, natural resources and economic development (Bansode et al., 2015).

\section{Exploration for genetic resources and the spread of crop plants}

The Special Report on Climate Change and Land (SRCCL) put together by the Intergovernmental Panel on Climate Change (the IPCC) concluded that keeping global warming to well below 2 deg.C could only be achieved by reducing greenhouse gas emissions from all sectors including land and food in the public and private sectors. However, the modest uptake of the most recent biotechnology and science for growing food is not yet ready to meet this new challenge to food production. The current agricultural technologies can only generate $20-40 \%$ of what is needed by as quickly as year 2030. The Consultative Group on International Agricultural Research (CGIAR)'s Research Program on Climate Change, showed that $11-21 \%$ of small-scale essentially subsistence farmers in Africa, Asia, and Latin America were already combatting climate change by changing their practices. This is where the role of genetic resources comes in.

Lettuce was a common oilseed crop in Upper Egypt as far back as 3000 B.C. as depicted by leaves painted on the walls of tombs at Thebes. The primitive lettuce type collected by UC Davis Professor Knowles (McGuire et al., 2012) was cultivated for its oilseeds and is unpalatable as a salad since the leaves are prickly and full of latex and hence bitter to taste. Nevertheless, such accessions have turned out to possess considerable resistance to several diseases of lettuce (especially downy mildew and mosaic virus) which affect the normal salad lettuce crop in Europe, North America, and Australia and have reportedly been utilized for improvement of iceberg type lettuce in California (Damania, 2008).

\section{Collections and conservation of genetic resources}

The best way to retain a comprehensive gene pool for future use in plant improvement is to collect and maintain the seeds of old landraces, rare forms, and wild relatives of crop plants from diverse native sources. With extensive cooperation between workers in diverse disciplines and in many countries, we can yet prevent permanent loss of remaining crop diversity and extinction of the wild relatives. In specific terms, plant explorations and collections have a dual role of making available for utilization the greatest possible amount of genetic variability in cultivated and wild species. At the same time they show us the range of variability that a species is capable of and its ecological as well as geographic range of distribution.

Wild or cultivated species near their centers of origin consist of several genotypes. Variability may be found for many traits rendering these plants valuable for use in breeding programs. Variability within a population is partially related to the mode of reproduction. The pattern of genetic differentiation within species is strongly associated with environmental heterogeneity. 
Genetic variability is governed by several factors including special isolation, population size, and mechanisms that regulate gene flow within the population.

Three main principals guide the collection, conservation, and exchange of germplasm. First, when an international team of explorers collects samples, a sub-sample is left in the country of origin for use by the national genetic resources conservation program. Second, germplasm is made freely available to all bonafide scientists, and third, all collections are multiplied and duplicated at another location for safety.

The largest of Costa Rica's reserves, Talamanca Biosphere Reserve, is a mosaic of more than 500,000 ha which includes three national and international (with Panama) parks, five Indian reservations, and two large forest reserves. Talamanca, which contains some of the richest biodiversity of plant and animal life in all of Central America, is part of the Man and Biosphere (MAB) Program (Dyer and Holland, 1988).

\section{Gene Banks and utilization of genetic resources}

Until the 1960s, most of the collections of crop plants were held as in the industrialized countries in the west who financed crop collection missions to the areas of diversity, especially for the major cereals. In some temperate countries, such as England, tropical and other plant species were preserved in open plots or glass houses or seeds. The former Soviet Union gained an early lead in collecting and conserving plant genetic resources as a result of the outstanding work of N.I. Vavilov, who set up the Institute of Plant Industry (VIR) at St. Petersburg (formerly Leningrad) (Vavilov, 1992).

By the 1960s it became apparent that more collecting and preservation for the genetic resources of the tropical and sub-tropical crops. The Food and Agriculture Organization of the United Nations (FAO) organized the first technical conference on plant exploration and introduction and set up a panel of experts to look into the problem of vanishing genetic resources. They recommended that a global network of crop genetic resources conservation centers (gene banks) be established. In 1972 the CGIAR convened a working group at Beltsville, Maryland, which urged the creation of the International Agricultural Research Centers (IARCs) for the collection and conservation of the germplasm of the world's most important food and feed crops. The International Board for Plant Genetic Resources (IBPGR), with headquarters at Food and Agriculture Organization (FAO), Rome, Italy, was an outgrowth of the CGIAR's involvement in this global effort.

Agriculture is a relatively recent historical phenomenon that began just over 11,000 years ago in the Near-East and later in Central America. But it is only in the present century that rapidly increasing world population has demanded that farmers produce more food than what is enough to feed their own families. Through the increase of food after the beginning of the agricultural (Neolithic $=$ food producing) revolution, the human species has incredibly multiplied its own numbers at the expense of the rest of the world's biota.

The world human population in 1900 was a little over 1.2 billion. By 1980 it was approximately 4.5 billion and a decade later it had jumped to 5.3 billion and in 2050 it is expected to double yet again to 10.5 billion! These population increases will largely be in the developing countries whose farmers cannot produce enough from indigenous varieties to meet the demand for food. A major breakthrough in the biotechnology will be needed to boost food production by 218 percent if the same number of calories (at 1990 levels) in the diet of developing countries is to be maintained. The million dollar question uppermost in the minds of heads of governmental bodies all over the world is that will we be able to feed such number?

The answer, according to me, is yes. Food output can be increased dramatically through the use of high-yielding varieties, irrigation, and application of fertilizers and pesticides as has been demonstrated in the past. At present, $25-30 \%$ of the harvest is lost due to improper storage conditions and marauding rodents in most developing countries. Improved storage and distribution systems would leave more food available to consumers. Availability of arable (cultivable) land can be boosted by reclamation of deserts and deforestation. Digging of tube wells to tap large reservoirs of ground water can also be attempted. The improved availability of water will lead to the 
production of more than one or two crops per season. For example, farmers on the banks Yangste River in China grow three crops per season relying on early maturing varieties to achieve this feat. Also improved crop rotation between cereals and nitrogen fixing legumes can boost yields in the former. All this can be achieved while keeping mounting human numbers, rising poverty and environmental degradation to acceptable levels.

Some people, ignorant of the way plant research operates, seem to think that governments should not be spending more research money on a surplus crop such as wheat. To such thinkers world renowned U.S. wheat breeder Orville A. Vogel (1990) had this to say: "Its because of solid research progress that we have a stable wheat production and even a surplus. Once research has been closed out for external reasons such as surpluses, the project is mothballed and the researchers may be dispersed. When economic conditions change, our research priorities will be re-ordered. We need to be continuously at work, and we need highly trained research personnel at our major public and private experiment stations. The public can ill afford to vacillate in its support for research designed to maintain affordable (crop) production."

The mosaic virus has brought the cane (Saccharum officinarum Linn.) sugar industry to the brink of disaster in many countries. In 1926 attacks of this virus in the state of Louisiana brought production down to 42,638 metric tons of refined sugar from a high of 181,440 tons. Introducing resistance genes from a wild relative, Saccharum spontaneum Linn., solved the problem. This cross was first made in Java in 1921 following a similar attack there.

In 1974 a single wild alfalfa plant (Medicago hemicycla Grossheim), was found to have resistance to all four biotypes of Stemphyllium leafspot disease that was causing huge losses to alfalfa in California. Soon after the genes for resistance were transferred to cultivated type of alfalfa by UC Davis Department of Agronomy Professor Ernest H. Stanford.

Coffee is the single most commercially traded plantation crop and revenues from it are only second to fossil oil in trade. Diseases of coffee affect the markets as production drops. In order to strengthen disease resistance coffee breeders have to resort to the use of wild coffee genetic resources (Damania, 2003).

Durum wheat (Triticum turgidum ssp. durum) has been grown in the U.S. for over 120 years. The cultivation during that time has moved northwards till North Dakota. But due to climate change and the requirement of this crop for colder temperatures, the center of production has moved in to Canada (Pardey et al., 2010).

Another example of use of old and obsolete genetic resources of wheat varieties to combat diseases and climate change comes from Triticum dicoccon Schrank (Zaharieva et al., 2020). In India it is known as "Khapli" wheat and is a known sources of resistance to Erysiphe graminis f. sp. tritici (Briggle, 1966).

Tomato (Lycopersicon esculentum L. Mill) is a world-wide crop that could be affected by climate change. In the recent past, wild relatives of tomato have been used for cultivar improvement. Rick and Fobes (1975) chose the oldest accessions of wild tomatoes collected from Latin American countries. They found that the oldest accessions of tomato and their closely related species harbored allozyme variation that could be used to combat climate change.

\section{Crop improvement and climate change}

Climate change poses a considerable to agriculture worldwide, but it has not been met with a similarly improved understanding of how best to utilize genetic resources to respond to this threat. Genetic resources were collected from their centers of diversity for future use in case the environment changes. This has now happened. And for the thousands of samples lying frozen in genebanks, their time has come. For example, shifts in crop climates in Sub-Saharan Africa have been predicted to be complete by 2050 (Burke at al., 2009), The implications for agricultural adaptation, with particular focus on identifying priorities in crop breeding and the conservation of crop genetic resources need to be addressed. It has been found that for three of Africa's primary cereal crops - maize, millet, and sorghum - expected changes in growing season temperature are considerable and dwarf changes projected for precipitation, with the warmest recent temperatures 
on average cooler than almost 9 out of 10 expected observations by 2050. For the "novel" crop climates currently unrepresented in each country but likely extant there in 2050, we identify current analogs across the continent. The majority of African countries will have novel climates over at least half of their current crop area by 2050 . Of these countries, $75 \%$ will have novel climates with analogs in the current climate of at least five other countries, suggesting that international movement of germplasm will be necessary for adaptation. A more troubling set of countries - largely the hotter Sahelian countries - will have climates with few analogs for any crop. Finally, we identify countries, such as Sudan, Cameroon, and Nigeria, whose current crop areas are analogs to many future climates but that are poorly represented in major genebanks - promising locations in which to focus future genetic resource conservation efforts (Burke et al., 2009).

Crop plant genetic resources will be vital in adapting crop production to the effects of climate change. Diverse species, varieties and cultivation practices allow crop to be cultivated across a wide range of environments. The landraces are well adapted to current conditions in their local areas. The challenge in the future will be to maintain a good match between crops and their production environments as the effects of climate changes increase (Jarvis et al., 2015). Crop production in all countries relies heavily of genetic resources of individual crops from all over the globe. This dependency is likely to increase due to climate change. Altered climatic conditions will mean that those crops that were traditionally grown may no longer be suitable and hence better-adapted crop varieties will need to be brought from elsewhere. Burke et al.., 2009 predict that by 2050 many countries in Africa will experience unique climatic changes that are not currently found within their borders. Well evaluated and documented germplasm will be essential in adapting varieties to the novel climates.

Changing precipitation patterns due to climate shifts leads to severe water shortages in some places or flooding in others. Thus the farmer will be forced to change crop growing seasons which affects food security. A temperature rise of just 2 deg. $C$ will increase rates of extinction of habitats and the crops and wild progenitors they harbor (Kumar, 2015)

The current situation in crop breeding demands continual evolutionary studies and mobilization of new and different sources of germplasm. Most of these potential sources incorporate the true landraces, primitive cultivars and the wild relatives from the primary gene pool. Today we have the possibility, through genetic manipulation, to engineer a plant that is easy to cultivate over several environments with nutritionally complete food in the seed that stores well, leaves that can be used as a vegetable, stems that fuel the fire, and roots that bake like bread. The best potential new crops are the as yet unused genes in our basic crops.

There are three ways in which primitive and wild genetic resources of our cultivated cereal crops can be utilized for improvement: 1 . Introductions for direct use as crops. 2 . Introductions that can confer particular traits to the adapted cultivars such as, disease resistance, protein content, etc. This type of utilization is the most prominent way in which primitive forms can be utilized and the only way for the wild relatives. 3. Introductions to increase yield per se, irrespective to resistance to physical or biotic stresses present in the environment.

However, the wild species remain the least collected, conserved and exploited category of germplasm, especially from the secondary gene pool. The extent of evaluation and initial usage (sometimes called "enhancement") among the three categories of germplasms are almost proportional to the degree of utilization.

Scientists screen germplasm for resistance to insect and disease attack and for tolerance to abiotic stresses such as, frost, heat, drought, and soil salinity. Whenever possible, breeders attempt to introduce resistance to a broad range of diseases and pests into a crop so that yields will be more stable. Also, any gains in crop improvement are longer lasting if more than one gene coding for disease or stress tolerance is involved. Therefore, gene banks are more useful if collections are evaluated and documentation is freely available.

Plant breeders mostly use breeding material with known agronomic data and background. They are reluctant to cross their successful commercial varieties, even after these have begun to deteriorate in performance, with a very primitive landrace or wild species simply because they do 
not want to introduce undesirable genes into their breeding program. Lack of information on genetic stocks with stable desirable genes or gene combinations and the unavailability of substantial seed quantities are additional impediments in the use of these germplasms.

It becomes obvious that if greater use of primitive and wild material has to be made it becomes essential to remove (or at least suppress) the close linkage between desirable traits and unfavorable alleles. This may be done through transporting the germplasm to areas similar to the native habitats where selection can be carried out under favorable conditions of soil, photoperiods and temperatures. For wild species, particularly the putative progenitors, either a naturally introgressed population or an artificially directed backcrossing program would improve their chances of inclusion in a breeding program. This preparatory activity is often referred to as germplasm enhancement or pre-breeding.

The assessment of use of germplasm collections in crop improvement for the major cereals has revealed the following:

1. The use of exotic germplasm; the successful use of landraces and wild species in cereals has been more extensive in the developed countries, which lack indigenous germplasm, than in the developing countries. This has been partially due to the fact that exploitation of these germplasms was undertaken earlier by the former. After the creation of the IARCs the benefits of such germplasms have improved crop production on a global basis. In fact, the IARCs have contributed substantially to collaborative generation and exchange of improved germplasm with the national programs and other institutions.

2. Constraints to the use of exotic germplasm; many plant breeders have been reluctant to devote a greater part of their resources for the exploitation of landraces, obsolete cultivars and wild species in the past. This was because the potential value of these germplasms was not fully known. Insufficient germplasm pre-breeding and lack of feedback from users are other reasons often cited for poor utilization of these genetic resources. However, with the use of biotechnology and creation of stable lines this situation is rapidly changing.

3. Support for genetic resources conservation programs; extensive use of landraces, primitive forms and wild species appears more tenable when the process of conservation, evaluation and exchange of germplasm is strengthened and adequately funded. Improved communication channels can also augment breeders' use of exotic genetic resources.

4. Use of computers and program packages; computer programs designed for analyzing large quantity of evaluation data have greatly reduced time and effort needed for arriving at tangible conclusions. This in turn has led to the publication of germplasm catalogues which have greatly facilitated dissemination of information on germplasm collections to actual users, thus encouraging greater utilization of services rendered by gene banks.

5. Applications of biotechnology; Research has been in progress for hybridizing unrelated plants and even micro-organisms by techniques such as somatic cell fusion as is being investigated in potato improvement, or by what are called "wide crosses" as in hybrids between corn (Zea mays L.) and sorghum (Sorghum bicolor (L.) Moench). Another more recent development in the use of biotechnology for crop improvement is the "FlavrSavr®" tomato (developed by Calgene in Davis, California in the 1990s) that had an unusually long shelf-life. Cotton farmers all over the world, including the U.S., were suffering heavy losses in yields due to the cotton bollworm (Helicoverpa armigera Hubner) pest. A new cotton variety developed by biotechnologists called 'Bollard' was genetically engineered to contain a particular gene from soil bacteria, 
Bacillus thuringiensis, which helps the cotton plant to create toxins that are fatal to the bollworm. This Bt cotton varieties, were first introduced to Asia in China in 1997. Since then the area of cultivation has increased to 1.5 million hectares in 2001, which is more than 35 percent of the total cotton area in China. Such successful research show us the value of maintaining gene banks and the benefits derived from the study of gene synthesis and recombinant DNA, collectively labeled biotechnology.

Global warming and the consequent climate changes result in mostly negative effects on agriculture, natural resources, environment, human health and economic development. The melting of polar ice caps and glaciers leads to a rise in sea levels. By the year 2100, which is not too far away, sea levels are expected to rise up to 0.59 meters (IPCC, 2001).

However, secure and long-term financial resources are very rarely made available for genetic resources conservation programs. This is because governments continually reassess priorities and political gains and redirect research funding to other uses. The gene banks coordinated by the CGIAR, thankfully, have a reasonable time frame of operation because of the nature of the CGIAR's mandate and the commitment of member governments. In 1990 Congress asked the U.S. Agency for International Development (USAID) to study the need for ex situ conservation of biological diversity and programs that the U.S. government could support. Recommendations were made and subsequently acted upon.

\section{Conclusions}

New genetic resources and technological breakthroughs are being employed to develop dedicated bioenergy crops (DECs) with better GHG profiles and with a suite of eco-physiological traits to maximize radiation interception, water- (WUE) and nutrient-use efficiencies (NUE), improved lingocellulosic accessibility to enzymatic degradation, and to confer environmental sustainability. Large-scale bioenergy crop plantations pose both opportunities and challenges, and will inevitably compete with food crops for land, water, nutrient resources and other inputs; whereas, biodiversity consequences of increased biofuel production will most likely result in habitat loss, increased and enhanced dispersion of invasive species, and pollution. Recent genetic modifications and breeding efforts of bioenergy crops aim at improving biomass yield, quality, and conversion efficiency. Improvements in composition and structure of bio-chemicals in bioenergy crops will enable the production of more energy per ton of biomass and will improve its caloric value, GHG profile, and GCC mitigation potential (Jaradat, 2010).

Since the centers of crop plant diversity of many important and not so important crops are in the developing countries of the Southern Hemisphere, the industrialized as well as non-industrialized world have a large stake in the success of genetic resources conservation programs. Most of the gene banks around the world now store germplasm of only the major food and some industrial crops. Other materials such as timber, medicinal plants, marine animals, and even microorganisms such as nitrogen fixing bacteria and yeast are largely neglected. Tropical crops are also, on the whole, neglected. For example, banana and coconut are major food crops in Asia and Africa and although plantation crops may be left to commercial interests for further development, few corporations have shown interest in establishing gene banks for these crops. The reason is simple. Gene banks are costly to operate and economic returns are not visible immediately.

Clearly plant improvement and changes in strategies due to climate change will be a major factor in meeting the immediate challenge of optimizing agricultural productivity in the coming decades. The high yielding varieties of wheat and rice such as PV-18 and IR-8, respectively, were the first in a series of plant breeding advances. In future plants will have to become more efficient in converting sunlight into usable food energy and at the same time be more resistant to biotic and abiotic stresses and less dependent upon high levels of soil fertility. A successful newly improved variety as a result of plant breeding is transitory. For example, a wheat variety newly released has an effective life of about 10 years because after billions of plants are grown they inadvertently invite evolution of a fresh combination of pathogens. At such time a new resistant strain needs to be bred. 
And the cycle goes on. Hence crop improvement is a continuously evolving process (Heisey and Kelly, 2015).

A possible break in this cycle has occurred due to the radical new technology now available in plant breeding. Modern techniques such as somatic cell fusion, anther culture and haploid breeding in cereals, could serve as a powerful tool towards reducing research time and can expand considerably the horizon of plant improvement. Tissue culture could also act as a bridge for molecular biology to also serve plant improvement.

In the future the usefulness of a gene bank will depend on the mapping of the relevant genes and their symbols. Given the enormous benefits which can be derived from biotechnology and genetic engineering, gene banks have an extremely important role to play in guaranteeing global food security and deserve greater support of governments, universities and the private sector than at present.

We, humans, utilize only a fraction of edible plant species which nature makes available to us in the world today. There are several scores of plants that could be used for human consumption and we will develop a need for them when the right time comes. Necessity is the mother of invention. This has happened in the past when man domesticated wild relatives of wheat, rice, maize and potato. Nothing prevents this from happening again except degradation of naturally occurring biodiversity that has been till now been carefully nurtured by our ancestors.

The demand for food in the industrialized world has reached saturation levels. Only $2 \%$ of the U.S. population engages in agriculture, the products of which are more than sufficient to feed the nation, and then some. In some western European countries, too we have the problem of over production coupled with zero or negative population growth. Increasing health concerns have led to drop in calories intake from animal products. As prices of agricultural produce get lower the above developments could also mean that more food will be available for the rising populations of the developing economies of the world. The only barrier could be the inability of governments to formulate and enforce effective policies that address the challenges posed to humankind today and in the future. As Herbert Clark Hoover, the 31st President of the U.S. had said in 1943 "The first word in war is spoken by guns. But the last word has always been spoken by bread".

The U.S. founding fathers recognized the value of plants in fulfilling the food, medicine, and fiber requirements of coming generations. Thomas Jefferson (1743-1826) the third president of the U.S., in one of his speeches on the needs of the new and growing country, is quoted as saying "The greatest service which can be rendered any country is to add a useful plant to its culture". The importance of that contribution is more relevant than ever today than it was 200 years ago when the U.S. president uttered those words.

Author Contributions: Dr. A.B. Damania has been in the field of Crop Genetic Conservation and Utilization since 1974. He has served various international organizations as a germplasm collector, evaluator, and a pre-breeder. During the last two decades he has been at the University of California's Genetic Resources Conservation Program (GRCP) working under Professor Calvin O. Qualset. During this period he has organized, among other, the Jack R. Harlan Symposia. He has brought all these knowledge on genetic resources to this paper. Inputs given to him with personal communications, books, etcc., from Emeritus Professor Calvin Qualset, Distinguished Professor Paul Gepts. Of the Departmenrt of Plant Sciences, and World Food Prize winner Dr. Gurdev S. Khush are gratefully acknowledged.

Funding: This research received no external funding.

Acknowledgments: The author wishes to acknowledge the support of the Department of Plant Sciences at University of California, Davis.

Conflicts of Interest: The authors declare no conflict of interest.

\section{References}

1. Kumar, S. 2015. Impact of Climate change on plant genetic resources. Researchgate, March 2015.

2. Muminjanov H., Karagöz, A. 2018. Biodiversity on Turkey. Contribution of genetic resources to sustainable agriculture and food systems. FAO, Ankara. 222 p. 
3. Jarvis, A., Lane, A., Hijmans, R. 2008. The effect of climate change on crop wild relatives. Agri. Ecosystems and Environment. 126:13-23.

4. Hole, F. 1998. The spread of agriculture to the Eastern Arc of the Fertile Crescent: Food for the herders. In The Origins of Agriculture and Crop Domestication, Proceedings of the Harlan Symposium on Origins of Agriculture and Domestication of Crop Plants in the Near East, held at ICARDA, Aleppo, Syria, 10-14 May, 1997. A.B. Damania, J. Valkoun, G. Willcox, and C.O. Qualset (Eds.), ICARDA, IPGRI, FAO, and GRCP, 1998, pages 83-93.

5. Damania, A.B. 2008. History, achievements, and current status of genetic resources conservation. Agronomy J. 100(1): 9-21.

6. Pfender, W.F., Vollmer, S.S. 1999. Freezing temperature effect on survival of Puccinia graminis subsp. Graminicola in Festuca arunndinacea and Lolium perenne. Plant Disease 83: 1056-1062.

7. Martynov, S.P., Dobrotvorskaya, T.V. 2006. Genealogical Analysis of Diversity of Russian Winter Wheat Cultivars (Triticum aestivum L.). Genet Resour. E Crop Evol. 53: 379-386.

8. Bansode, R., Kumar, S., Mol, S.A., Malav, L., Malav, M.K., Kharia, S.K. 2015. Impact of climate change on plant genetic resources. International J. Ext. Res. 3:6-9.

9. McGuire, P.E., Damania, A.B., C.O. Qualset (Eds.). 2012. Safflower in California. The Paulden F. Knowles personal history of plant exploration and research on evolution, genetics, and breeding. Agronomy Progress Report no. 313, Dept. of Plant Sciences, university of California, Davis, CA, USA. 44 p.

10. Dyer, M.I., Holland M.M. 1988. UNESCO's Man and Biosphere Program. BioScience 39 (9) (Oct., 1988): 635-641.

11. Vavilov, N.I. 1992. Origin and Geography of Cultivated Plants. Cambridge Univ. Press, Cambridge, UK.

12. Vogel, O. 1990. Research the staff of life. Agric. Research 38(6): 2.

13. Damania, A.B. 2003. The early history and spread of coffee. Asian Agri-History 7(1): 67-74.

14. Pardey, P.G., Alston, J.M., Babcock, B.A. 2010. The Shifting Patterns of Agricultural Production and Productivity Worldwide. Midwest Agribusiness Trade Research and Information Center, Iowa State University, $482 \mathrm{p}$.

15. Zaharieva, M., Ayana, N.G., Hakimi, A.A., Misra, S.C., Monneveux, P. 2010. Cultivated emmer wheat (Triticum dicoccon Schrank) an old crop with promising future: a Review. Genetic Resourc. E Crop Evol. 57: 937-962.

16. IPCC, 2001. Climate change 2001: The scientific basis. In: Contribution of working group I to the Third Assessment Report. Intergovernmental Panel on Climate Change (Eds. J. Houghton, et al.) Cambridge Univ. Press, UK.

17. Briggle L.W. 1966. Transfer of resistance to Erysiphe graminis f.sp. tritici from Khapli emmer and Yuma durum to hexaploid wheat. Crop Sci. 6(5): 459-461.

18. Rick, C.M., Fobes, J.F. 1975. Allozyme variation in the cultivated tomato and closely related species. Bull Torrey Bot Club 102: 376-386.

19. Burke, M.B., Lobell, D.B., Guarino, L. 2009. Shifts in African crop climates by 2050, and the implications from crop improvement and genetic resources conservation. Global Environmental Change 19: 317-325.

20. Jarvis, A., Upadhyaya, H., Gowda, C.L.L., Agrawal, P.K., Fujisaka, S., and Anderson, B. 2015. Plant genetic resources for food and agriculture and climate change In FAO 2015 Coping With Climate Change - The Roles of Genetic Resources for Food and Agriculture. Rome, Italy, 9-21.

21. Jaradat, A.A. 2010. Genetic resources of energy crops: Biological systems to combat climate change. Australian J. Crop Sci. 5: 309-323.

22. Heisey, P.W., Kelly D.R. 2015 Using Crop Genetic Resources To Help Agriculture Adapt to Climate Change: Economics and Policy, EIB-139, U.S. Department of Agriculture, Economic Research Service, April 2015. 